\title{
Past, present and future
}

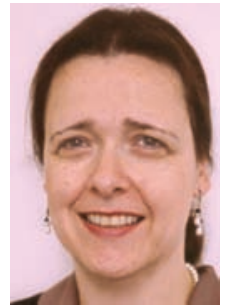

\section{A.K. Simonds}

Royal Brompton Hospital Sydney Street London SW3 6NP UK

Fax: 442073518911

E-mail:a.simonds@rbht.nhs.uk

The pianist-turned-poet Alfred Brendel

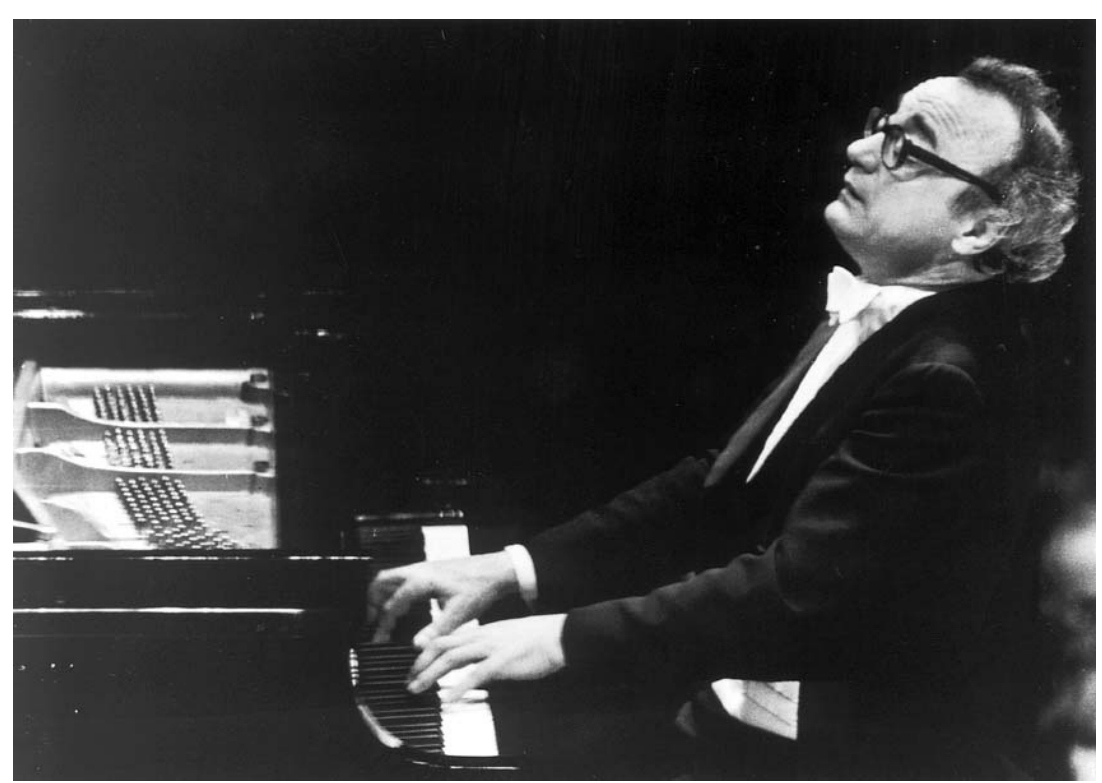

will be inevitably in the forefront of dealing with these potential disasters. We start with reviews on bird flu and SARS. Further updates on the translation of research development to clinical application will follow. Reviews on overlap areas such as developments in cardiology, intensive care and palliative care medicine are planned. Subsequent issues will include a series on mechanical ventilation in chronic obstructive pulmonary disease (COPD) covering intensive care unit (ICU) care and "Ask the Expert" sections on non-invasive ventilation in COPD and lung cancer. Your questions on these areas are invited in this issue. I am very grateful to each of the ERS Assemblies for submitting Hot Topics to keep readers abreast of key recent respiratory developments in their areas.

In this issue we take you on an eclectic journey from President Bush's cough syncope to difficult asthma. Both intractable cough and brittle asthma are challenging problems to deal with in the busy clinic, yet a systematic approach yields dividends. As Professor Morice points out, cough affects around 10\% of individuals and $7 \%$ report a significant impact on daily activities. There is social and collateral damage too; Alfred Brendel [2], the classical pianist turned poet, bitterly complains of the "coughers and clappers of Cologne" who interrupt performances by coughing distinctly during expressive silences.

As well as new guidelines on the management of cough, recommendations on air travel in respiratory patients have recently been updated. Drs Robson and Innes dissect this advice and examine the practical consequences for our patients.

At first sight, telemedicine may seem to have little relevance to current everyday practice, yet with the growing emphasis on community management, new thinking is needed to bridge hospital and local care. It doesn't have to be 


\section{EDITORIAL}

complicated, either. How about substituting alternate outpatient clinic visits with a telephone consultation to reduce pressure on clinic wait times? Transmission of arterial oxygen saturation data from home can allow titration of oxygen flow rates and guide exacerbation therapy in severe COPD patients. Michaele Vitacca explains how he has even used telemedicine data to support the wishes of end-stage ventilator-dependent motor neurone disease patients to remain at home. Much is possible technologically, but no new approach will work unless patients, families and medical teams are confident and competent with the communication processes involved. Crucially, as the article concludes, there is as much need to assess telemedicine in terms of costeffectiveness and its impact on health burden and quality of life as any other medical intervention, and adapt it to specific disease and local needs rather than simply apply yet another layer of care.

I am very grateful to Pat Haslam, Kai-Håkon Carlsen, Jean-Luc Eiselé, Pippa Powell and the brilliant Editorial team who were midwives to Breathe. The ERS has a pioneering reputation in developing educational resources so that material is available as PDF downloads, Powerpoint

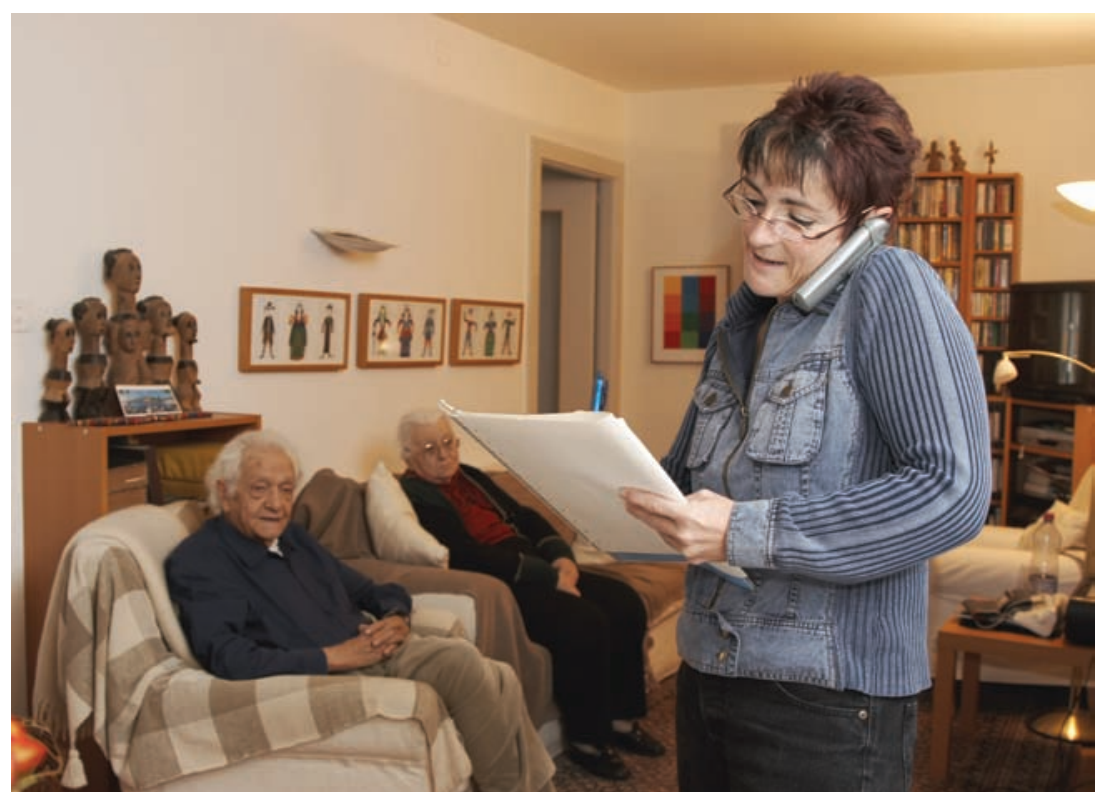

slides for teaching and podcasts; and CME assessments will soon be online. Breathe can be used in all these formats, but there probably remains a place for an educational journal that can be read on the train, at the airport waiting for a delayed flight, in the garden or by the fireside after a long day at work. We hope to make that effort worth your while.

\section{References}

1. Hartley LP. The Go-Between. London, Hamish Hamilton, 1953; London, Penguin Books, 1958.

2. Alfred Brendel. The Poem. The Coughers of Cologne from One Finger Too Many Faber Poetry Series 1998. 